\title{
EVALUATION OF ORAL AND EXTRA-ORAL FACTORS PREDISPOS- ING TO DELUSIONAL HALITOSIS
}

\author{
O. AKPATA, ${ }^{1}$ O. F. OMOREGIE, ${ }^{1}$ K. AKHIGBE ${ }^{2}$ AND E. E. EHIKHAMENOR ${ }^{3}$ \\ ${ }^{1}$ Department of Oral maxillofacial Surgery and Pathology, University of Benin Teaching Hospital, Benin \\ City, Edo State, Nigeria. ${ }^{2}$ Department of Mental Health, University of Benin Teaching Hospital, Benin City, \\ Edo State, Nigeria and ${ }^{3}$ Department of Restorative Dentistry, University of Benin Teaching Hospital, Benin \\ City, Edo State, Nigeria.
}

\author{
Corresponding Author: \\ Omoregie Osawe Felix \\ E-mail: \\ omoregiefo@yahoo.com \\ Conflict of interest: \\ None declared
}

\section{SUMMARY}

Objective: This study evaluated the role of patients' associated oral and extra-oral factors, as well as previous dental treatment, as possible predisposing (triggering) factors in the development delusional halitosis.

Method: Forty-six patients diagnosed of delusional halitosis, over a consecutive period of 2 years (20032004) were selected for this study. Diagnosis was based on: use of standard halitosis questionnaire (to confirm the presence of psychological component) modified to obtain data on oral and extra-oral factors, as well as previous dental treatment linked by patients as cause of oral malodour; clinical assessment without objective evidence of oral malodour; absence of reliable third party to confirm patients' claim of oral malodour; and screening with sulphur monitor (RH-17 Series Halimeter, Interscan, Chatsworth, CA) that was within normal range (80-140ppb).

Results: All the 46 patients studied had normal halimeter measurement and no reliable third party to confirm the patients' claim of oral malodour. Twenty-four (52.2\%) patients had associated possible predisposing factors. The most common associated factors were bitter taste $(25.0 \%)$, oral deposits (20.8\%), carious tooth $(16.7 \%)$ and previous tooth extraction (16.7\%). Associated factors were divided into oral, extra-oral and dental treatment. Patients' associated oral factors were significantly correlated as predisposing factors for delusional halitosis $(\mathrm{p}<0.01)$

Conclusion: This study shows significant correlation of patients' associated oral factors as the triggering event, which could predispose those individuals who may have underlying psychosomatic tendencies to developing delusional halitosis.

Keywords: Predisposing factors, delusion, halitosis, oral malodour, psychosomatic predisposition

\section{INTRODUCTION}

Delusional halitosis also referred to as psychosomatic halitosis occur in apparently healthy individuals who complain of chronic bad breath that no one else can smell, for which no local or systemic disease causing oral malodour could be found. ${ }^{1,2}$ But little is known about the associated and possible predisposing factors in the aetiology of delusional halitosis. Conversely, several aetiologic factors have been reported in the pathogenesis of genuine halitosis, which has been useful in the diagnosis and treatment of this condition. These oral and systemic factors have been associated with odorous gases, such as volatile sulphur compounds, volatile aromatic compounds, organic acids and amines in the air expelled from oral cavity. ${ }^{3-7}$.

However, patients with delusional halitosis easily misinterpret other people's behaviour such as covering of the nose or averting the face as an indication that their breath is offensive. ${ }^{1}$ These patients' perception of another individual's attitude may be due to their delusion, which may have accelerated the development of psychosomatic halitosis. These individuals are concerned with their own bad breath without actually exhibiting oral malodour, possibly due to latent psychosomatic tendencies and mental immaturity. ${ }^{8}$

Some patients with delusional halitosis claim that oral and/or extra-oral condition or previous dental treatment may have been the cause of their bad breath. To the best of our knowledge, no study has been carried out to ascertain the relationship of these factors to the development of delusional halitosis. But, it has been reported that triggering events, facilitated by feeling of anxiety or depression could result in hearing of voices, which was strongly associated with formation of delusion in older children. ${ }^{9}$ Also, deformity from diseases or surgical treatment has been identified as possible cause of stress, which could trigger the development of psychosomatic illness. ${ }^{10}$

This study evaluates the role of patients' associated oral and extra-oral factors, as well as previous dental treatment, as possible predisposing (triggering) factors in the development of delusional halitosis amongst 

tre, University of Benin Teaching Hospital, Benin City, Nigeria.

\section{PATIENTS AND METHODS}

During a consecutive period of two years (2003-2004), 46 patients diagnosed of delusional halitosis were selected for this study amongst patients who presented with history of chronic bad breath at the Dental Centre, University of Benin Teaching Hospital, Benin City, Nigeria. Diagnosis was based on: use of standard questionnaire for halitosis to confirm the presence of psychological component (psychological scores between 4 and 10) ${ }^{11,12}$ and modified to obtain data on patients' associated oral and extra-oral factors, as well as previous dental treatment linked by patients as cause of their oral malodour; clinical examination ${ }^{12}$ without objective evidence of oral malodour; absence of reliable third party (a spouse, close relative or friend of the patient) to confirm patients' claim of oral malodour; and screening with sulphur monitor (RH-17 Series Halimeter, Interscan, Chatsworth, CA) that was within normal range (80-140ppb). ${ }^{5}$ Routine scaling and polishing procedure, together with counseling was carried out for cases initially suspected to be pseudohalitosis. ${ }^{12}$ Amongst selected patients with abnormal taste, only those who linked their abnormal taste as possible cause of their oral malodour were included in the study.

Data collected were patient's age, gender, associated oral and extra-oral conditions, previous dental treatments and psychological scores. Age group and gender stratified all patients' data in decade. The frequency percentages of each age group were calculated and the sex incidence ratio of males to females was determined.

Table 2: Associated predisposing factors for delutional halitosis among patients $(n=24)$ in the study patients diagnosed of the condition at the Dental Cen-

The types of oral and extra-oral associated factors and previous dental treatments were outlined and their frequency percentages were calculated.

Data collected was transferred to excel 2000 edition and analyzed with Statistical Package for Social Sciences (SPSS). Multivariate analysis and statistical testing was used to estimate the strength of correlation of the associated factors (using Pearson's correlation). The confidence level was set at $99 \%$ and probability values ( $\mathrm{P}$-value) of $\mathrm{P}<0.01$ was regarded as significant.

\section{RESULTS}

Forty-six patients were diagnosed of delusional halitosis with confirmed psychological component (psychological scores $=4$ to 10 ). All the patients had normal halimeter measurement, and no reliable third party to confirm their claim of oral malodour. The age range of the patients was 16 to 48 years and majority of the patients were males within the age group of 21 to 30 years $(n=11,23.9 \%)$. Most females were within the age group of 41 to 50 years $(n=6,13.0 \%)$. There were 29 $(63.0 \%)$ males, and $17(37.0 \%)$ females, giving male to female ratio of $3: 2$ (Table 1 ).

Table 1: Age and Gender distributions of patients included in the study

\begin{tabular}{|l|c|c|c|c|}
\hline $\begin{array}{l}\text { Age } \\
\text { (year) }\end{array}$ & Male & $\begin{array}{l}\text { Fe- } \\
\text { male }\end{array}$ & $\begin{array}{l}\text { Freq } \\
\text { uency }\end{array}$ & $\%$ \\
\hline $11-20$ & 7 & 1 & 8 & 17.4 \\
\hline $21-30$ & 11 & 5 & 16 & 34.8 \\
\hline $31-40$ & 7 & 5 & 12 & 26.0 \\
\hline $41-50$ & 2 & 6 & 8 & 17.4 \\
\hline $\begin{array}{l}\text { Not speci- } \\
\text { fied }\end{array}$ & 2 & - & 2 & 4.4 \\
\hline Total & 29 & 17 & 46 & 100 \\
\hline
\end{tabular}

\begin{tabular}{|c|c|c|c|c|c|c|c|c|}
\hline Oral factor & $\mathbf{n}$ & $\%$ & Extra-oral factor & $\mathbf{n}$ & $\%$ & $\begin{array}{l}\text { Dental } \\
\text { Treatment }\end{array}$ & $\mathbf{n}$ & $\%$ \\
\hline Bitter taste & 6 & 25.0 & Mucous from the throat & 2 & 8.3 & $\begin{array}{l}\text { Previous tooth } \\
\text { extraction }\end{array}$ & 4 & 16.7 \\
\hline Oral deposit & 5 & 20.8 & Stomach discomfort & 1 & 4.2 & Tooth filling & 2 & 8.3 \\
\hline Carious tooth & 4 & 16.7 & Hot breath from the throat & 1 & 4.2 & $\begin{array}{l}\text { Delayed scaling and } \\
\text { polishing }\end{array}$ & 1 & 4.2 \\
\hline Salty taste & 2 & 8.3 & Emotional disturbance & 1 & 4.2 & Denture & 1 & 4.2 \\
\hline Coated tongue & 2 & 8.3 & Vaginal Discharge & 1 & 4.2 & & & \\
\hline Impacted tooth & 2 & 8.3 & Belching & 1 & 4.2 & & & \\
\hline Others & 6 & 25.0 & & & & & & \\
\hline
\end{tabular}


Twenty-four $(52.2 \%)$ patients had associated possible predisposing factors, while $22(47.8 \%)$ cases could not specify the cause of their presumed oral malodour. The associated factors were categorised into oral factors, extra-oral factors and dental treatment. The distribution of the associated factors is provided in Table 2. The other factors include toothache, excessive saliva, thick saliva, oily taste, sour taste and teeth space.

There was statistically significant correlation of patients' associated oral factors as predisposing factors to delusional halitosis $(\mathrm{P}<0.01)$. There was no significant association of extra-oral factors or dental treatments as predisposing factor to delusional halitosis $(\mathrm{P}>0.01)$.

\section{DISCUSSION}

In evaluating the possible predisposing factors to delusional halitosis, the patients selected for this study were those diagnosed to be suffering from delusional halitosis. The questionnaire administered confirmed the presence of psychological component in these patients. Nevertheless clinical assessment, breath measurement with the halimeter, routine scaling / polishing and counseling was performed to rule out the possibility of including individuals who had genuine halitosis or pseudo-halitosis with associated psychological component. ${ }^{11,12}$ Our findings shows that the condition occurred frequently in young male individuals, which is consistent with those reported as the characteristic features of delusional halitosis; an olfactory reference syndrome and a variant of monosymptomatic hypochondriacal disorder. ${ }^{1,13,14}$ In contrast, genuine halitosis is commoner in patients over 60 years of age, ${ }^{15,16}$ without gender prevalence or severity. ${ }^{17,18}$ This study suggests that young males were more predisposed to delusional halitosis; possibly, because they develop psychosomatic tendencies, such as social-phobia ${ }^{19,20}$ at a younger age, compared to females who were mostly affected at slightly older age.

Generally, patients with delusional halitosis fail to recognize their psychosomatic condition, but a number of them interpret other people's behaviour as response to their own bad breath. ${ }^{20,21}$ About half of the patients in this study associated their oral malodour with oral and or extra-oral factors or previous dental treatment. They believe that their condition would not improve until these factors were 'taken care of'. Oral factors, particularly abnormal taste, were the most common associated predisposing factor for delusional halitosis, followed by extra-oral factors and dental treatment. In this study, only oral factors were significantly associated as the triggering event, which could predispose the patients possibly with underlying psychosomatic tendencies to develop delusional halitosis. Therefore, we share the same opinion with Yaegaki et al ${ }^{12}$ that clinicians man- aging these patients should also focus on the underlying psychosomatic factors rather than patients own delusion. Specifically, the general dental clinicians are advised to counsel these patients according to the guideline for dentists managing patients with psychological problems, especially those suffering from dental anxiety. $^{22}$

The commonest associated oral factor was abnormal taste, with bitter taste as the most frequent in this group. It is a known fact that taste could be a predictor of bad breath ${ }^{23}$ and psychosomatic halitosis with the abnormal taste has occasionally been mismanaged with metronidazole and/or chlorhexidine mouthwash. ${ }^{12}$ Although, most of the patients with delusional halitosis had abnormal taste, only those that linked it to be possible cause of their oral malodour were reported in this study. It appears that abnormal taste could be an indicator of a possible psychological component in both genuine and psychosomatic halitosis. ${ }^{11,12}$ Oral deposit was the second most common oral factor. Some patients associated oral deposits on the teeth or gingival margin as the possible cause for their oral malodour. Although, clinically obvious oral deposit and the related periodontal disease ${ }^{5}$ have been implicated in the aetiology of genuine halitosis, clinical assessment of patients in this study showed very good oral hygiene and a normal breath measurement using the halimeter confirming that patients claim was inappropriate. The third most common oral factor was carious tooth, all of which have been either filled or extracted. The patients claim could not be substantiated clinically as none of them presently had carious lesion or objective evidence of oral malodour using the halimeter. However, dentists are advised to ensure adequate treatment of patients presenting with any of the above oral conditions and proactively counsel them about oral malodour, to preclude the possibility of developing psychosomatic halitosis.

A number of dental treatments, particularly tooth extraction and tooth filling, were associated as possible causes of oral malodour in this study. Similarly, some studies have associated dental therapy and surgical procedures with the development of psychosomatic diseases. ${ }^{10,24}$ Delusional halitosis may have occurred in these patients due to possible underlying psychosomatic tendencies, aggravated by stressful (triggering) event of dental treatment; but no strong association of dental treatment as a predisposing factor was observed in this study. However, we advise that dental procedures should be performed with minimal trauma and stress on patients. Also, patient's mental assessment may be necessary after undergoing stressful dental therapy, to determine if there was any serious psycho- 
logical effect of the treatment on the patients which should be managed by the mental health specialists.

Among the extra-oral factors associated as possible causes of oral malodour in these patients, only emotional disturbance has been linked with the formation of delusion in adolescents. ${ }^{9}$ While stress and emotion has been reported as triggers of psychosomatic illnesses. $^{25}$ There was an unusual case of a young female patient who linked vaginal discharge as a possible cause of her oral malodour. Further investigation of the case revealed that she had emotional problems with her male partner, with resultant psychological distress that might have triggered her supposed oral malodour. Patients, who relate their emotional state to be possible cause of their oral malodour, could benefit more from early referral to the mental health specialist for mental assessment and appropriate treatment.

In conclusion, the study shows significant correlation of patients' associated oral factors as the triggering event, which could predispose those individuals who may have underlying psychosomatic tendencies to developing delusional halitosis.

\section{REFERENCES}

1. Iwu C O, Akpata O. Delusional halitosis: Review of the literature and analysis 32 cases. Br Dent. J 1990; 168(7):294-96.

2. Akpata O. Omoregie F.O, Akhigbe K. Ehikhamenor E. Frequency of delusional halitosis in a university community. Benin Journal Postgraduate Medicine 2006; 8(1):8-11.

3. Scanz M, Roldan S, Herrera D. Fundamentals of breath Malodour. J Contemp Dent Pract 2001; 4 (2):1-17.

4. Goldberg S, Kozlovsky A, Gordon D., et. al. Cadaverine as a putative component of oral malodor. J Dent Res. 1994; 73(6):1168-72.

5. Yaegaki K, Sanda K. Volatile sulfur compounds in mouth air from clinically healthy subjects and patients with periodontal disease. J periodontal Res. 1992; 27 (4 Pt 1): 233-38.

6. Scully C, Porter R, Greenman J. What to do about halitosis? Br Med J 1994; 308: 217-18.

7. Preti G, Clark L, Cowart B J et al. Non oral aetiologies of oral malodor and altered chemosensation. J periodontal 1992; 63(9): 790-96.

8. Yaegaki K, Coil J.M. Clinical dilemmas posed by patients with psychosomatic halitosis. Quintessence Int 1999;30(5):328-33.

9. Escher S, Romme M, Buiks A et al. Formation of delusional ideation in adolescents hearing voices: a prospective study. Am J Med Genet 2002; 114(8):913-20.
10. Banon J N, Saad M N. Operative plastic and reconstructive surgery. Edinburgh, London Melbourne and New York, Churchill Living Stone, 1980:5-6.

11. Yaegaki K, Coil J.M. Clinical application of the questionnaire for diagnosis and treatment for halitoisis. Quintessence Int 1999; 30:302-06.

12. Yaegaki K, Coil J M. Examination, classification, and treatment of halitosis; clinical perspectives. $J$ Can Dent Assoc 2000 ; 66:257-61.

13. Pryse-Philips W: An olfactory reference syndrome. Acta psychriatr Scand 1974; 47:484-509.

14. Davidson M, Mukherjee S. Progression of olfactory reference syndrome to mania: a case report. Am J Psychiatry 1982; 139:1623-24.

15. Johnson $\mathrm{P} \mathrm{W}$. The olfactory reference syndrome and halitosis. In Van Steenberghe D, Rosenberg M. Bad Breath. A multidisciplinary approach. Leuven: Leuven University press, 1996:231-40

16. Newman M G. The role of periodontitis in oral malodour. Clinical perspective. In Van Steenberghe D, Rosenberg M. Bad Breath: A multidisciplinary approach. Leuven University press. 1996:3-14.

17. Iwakura M, Yasuno Y, Shimura M, et al. Clinical characteristics of halitosis: difference in two patient groups with primary and secondary complaints of halitosis. J Dent Res. 1994; 73(9): 156874.

18. Rosenberg M, Kulkarni G V, Bosy A, et al. Reproducibility and sensitivity of oral malodor measurements with a portable sulphide monitor: J Dent Res. 1991; 70(11):1436-40.

19. Tanaka N, Saito K, Amamiya A et al. Psychological Characteristics of patients of halitosis with psychogenetic factor-on the usefulness of Egogram as a therapeutic tool. Jpn J Psycho Dent 1988; 3:70-7.

20. Masui I. Perception and behaviors toward oral malodor and psychosomatic factors. Jpn J Dent Practice Administration 1997; 32:107-25.

21. Yaegaki K, Masui I, Sano S. et al. Studies for behaviour and perception towards oral malodour. Tsurumishigaku 1995; 21:457-66.

22. Lenton P, Majerus G, Bakdash B. Counseling and treatment of bad breath patients: A step by step approach. J Contemp Dent pract 2001;2(2):46-61

23. Bosy A. Taste as a Predictor of oral malodour. The International Conference on Breath Odour; Vancouver, BC, Canada. 1997: 1-6.

24. Uchida Y. Psychosomatic disease and dental therapy. Dent J 1983; 17:185-93.

25. Saheeb B D O, Otakpor A N, Sede M A. Mental health problems in dentistry. Ann Biomed Sci. 2002; 1: 1-9. 